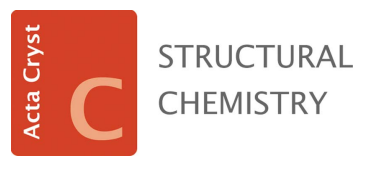

ISSN 2053-2296

eywords: book review; chemical elements.

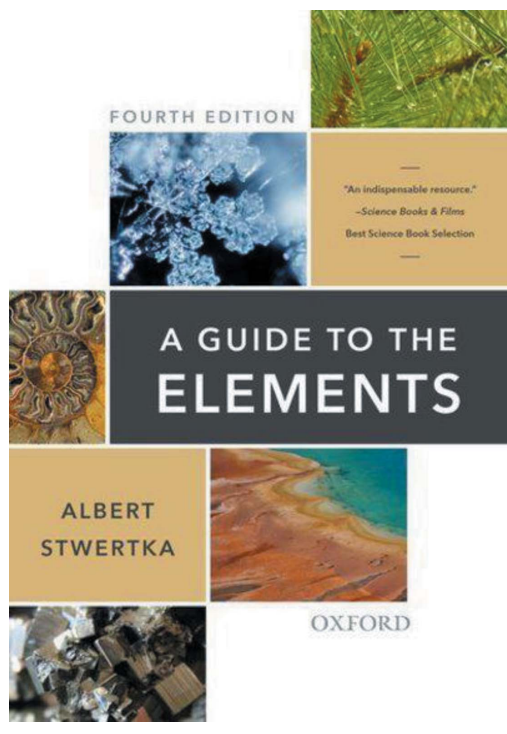

(C) 2019 International Union of Crystallography

\section{A Guide to the Elements. Fourth Edition. By Albert Stwertka. Oxford University Press, 2018. Hardback, Pp. 263. Price GBP 38.99. ISBN 9780190682347. Paperback Price GBP 19.99. ISBN 9780190682354}

\author{
Massimo Nespolo*
}

Université de Lorraine, CNRS, CRM2, Nancy, France. *Correspondence e-mail: massimo.nespolo@univ-lorraine.fr

A Guide to the Elements is an agile book aiming at providing a reference to the reader about the history, as well as the main chemical and physical properties, of the chemical elements. The target reader is the general public with some science background, rather than the accomplished chemist, as one immediately understands from the introduction, where basic definitions well known to the chemist are briefly introduced (for example, the periodic table, isotopes, atomic shells etc.).

The book has reached its fourth edition. I have not read the previous editions, but comparing the table of contents and the index available online for the third edition, it is not clear what changes have been introduced, apart from the conventional names for elements No. 113-118 which had not been assigned when that edition went to press. I therefore concentrate my review on the actual content rather than on the changes from the previous edition, which are not clear to me.

Each element gets at least one page, where its history, including sometimes some anecdotes, physical and chemical properties (not available for most transactinides), and use in daily life are described. Quite obviously, the most extensively used elements receive greater space (the record holder being carbon, with 7.5 pages) than the more exotic, artificial ones, but each and every element gets its spotlight. The amount of information condensed in this book is remarkable and the style in which it is presented is attractive, so that the reader never gets bored. The epilogue insists on the search for the 'island of stability' (the hypothetical region of the periodic table where giant elements with 184 neutrons and 120-126 protons would be unusually stable); it is followed by a glossary and a chronology of the discovery of the elements, and by a list of printed and online resources.

We notice, however, a few regrettable omissions which would have been important additions for the general public which is the target of this book:

- the use of $\mathrm{N}_{2} \mathrm{O}$ anaesthetic ('laughing gas') is discussed (page 47), but nothing is said about its deleterious oxidation effects on cobalamine (vitamin B12), which has been known for a long time (Chanarin, 1980);

- the three pages on oxygen say nothing at all about its toxicity, which is a serious omission in a general-public-oriented chapter devoted to the element;

- the same objection can be levelled at the chapter about fluorine, as well as at that about aluminium, the latter being explicitly defined as 'nontoxic' (page 63);

- when discussing gypsum (page 82), a word about it as a secondary product (e.g. phosphogysum) and the hazards related to its potential use (residual radioactivity) would have been useful;

- in the chapter about iridium, no mention is made of the iridium anomaly at the Cretaceous-Paleogene boundary taken as evidence for an asteroid impact (Alvarez et al., 1980).

A few mistakes should also to be pointed out:

- magnesite is incorrectly addressed as 'also known as dolomite' (page 60), which is simply incorrect;

- chromium sesquioxide $\left(\mathrm{Cr}_{2} \mathrm{O}_{3}\right)$ is said to be 'among the 10 most abundant compounds in the Earth's crust', which seems a gross overestimation, even ignoring silicates;

- similarly, barium is stated to rank '6th in abundance among the elements that make up the Earth's crust' (page 149), whereas it is only 14th. 
More care could have been taken to avoid apparent contradictions that may be misleading for the reader. Titanium is listed among the carcinogenic elements on page 83; when the reader then learns (page 85) that the same element is used in bone surgery, he may easily be puzzled.

Some of the applications of chemical elements described in the book seem of rather historical importance, but nothing is done to prevent the impression of actuality: the use of PVC for plastic bottles is now reduced or banned in at least some parts of the world, but reading page 74 one gets the impression it is the material of choice; the use of chromium for 'high-quality recording tapes' (page 90); multiple references to cathode-ray tubes (e.g. page 104); the use of mercury in thermometers (page 186); the use of lead in the glass screens of TV sets (page 191); Pluto still called a 'planet', despite being retrograded to a dwarf planet since 2006 .

The sentence ' $[\ldots]$ neodymium is isolated from its ores by ion exchange' in the chapters about thulium and ytterbium is probably a remnant of a copy-and-paste in the wrong place; or one should substitute the target element for 'neodymium' in the sentence.

Apart from these somewhat venial sins, a more fundamental doubt has to be expressed about the interest of publishing such a book at the approach of the third decade of the $21 \mathrm{st}$ century, when constantly updated online resources are available, against which the competition is lost in advance. Wikipedia has presently 13 pages (not counting the references) about carbon, i.e. about twice as many as in this book, and even eight pages (again, not counting the references) about oganesson versus two (including a big photo) in this book. The interest of this book has clearly declined since the publication of the first edition in 1996.

\section{References}

Alvarez, L. W., Alvarez, W., Asaro, F. \& Michel, H. V. (1980). Science, 208, 1095-1108.

Chanarin, I. (1980). J. Clin. Pathol. 33, 909-916. 